\title{
Diagnostic Accuracy of the Salzburg Electroencephalographic Criteria for Non-convulsive Status Epilepticus: A Retrospective Study Non-konvülzif Status Epileptikus Tanısında Salzburg Elektroensefalografi Ölçütlerinin Tanısal Doğruluğunun Retrospektif Değerlendirilmesi
}

\author{
Ebru Altındağ ${ }^{1}$, Betül Baykan ${ }^{2}$ \\ ${ }^{1}$ Istanbul Bilim University Faculty of Medicine, Department of Neurology, Istanbul, Turkey \\ ${ }^{2}$ Istanbul University Istanbul Faculty of Medicine, Department of Neurology, Istanbul, Turkey
}

Keywords: Non-convulsive status epilepticus, electroencephalography, coma

Anahtar Kelimeler: Non-konvülzif status epileptikus, elektroensefalografi, koma

\section{Diagnostic Accuracy of the Salzburg Electroencephalographic Criteria for Non- convulsive Status Epilepticus: A Retrospective Study}

Non-convulsive status epilepticus (NCSE) is a neurologic emergency that affects a wide spectrum of patients. The diversity of clinical presentation and unconsciousness of patients due to primary insult, especially in intensive care units, make NCSE impossible to be diagnosed without using electroencephalography (EEG). Although clinical and electrophysiologic diagnostic criteria have been developed, it is hard to diagnose NCSE even for experts in this field (1). Prior terminology was reviewed in the $4^{\text {th }}$ London-Innsbruck Colloquium on Status Epilepticus in 2013, and the "Salzburg EEG Criteria for NCSE" were reported by Leitinger et al. (2) (Table 1).

The same group retrospectively tested the diagnostic accuracy of the Salzburg criteria in their study titled "Diagnostic Accuracy of the Salzburg EEG Criteria for NCSE: A Retrospective Study" (3). Two hundred twenty patients aged over 4 months from 3 centers in 2 countries were included in the study. Participants were divided into two groups: 120 patients under clinical suspicion of having NCSE and 100 patients with abnormal EEG findings but no clinical suspicion of NCSE (the control group). Patients were evaluated just after arrival to hospital using all available clinical data except the Salzburg criteria and $36 \%$ was diagnosed as having NCSE. The 2 investigators then retrospectively used the Salzburg criteria and found that the sensitivity was $97.7 \%$, specificity was $89.6 \%$, and overall accuracy was $92.5 \%$. The positive and negative predictive values were $84 \%$ and $98.6 \%$, respectively. Three people in the control group were false positives. Inter-rater agreement was high. The investigators concluded that the Salzburg criteria were reliable and feasible.

Two issues were criticized by Roshdy and Saleh (4) in their letter published in Lancet's Neurology very recently. First, NCSE has 2 major subgroups that differ from each other in terms of clinical course and prognosis. Diagnosis of absent status epilepticus, which is characterized by $>3 \mathrm{~Hz}$ spike wave discharges in a patient with known epilepsy is not hard, but patients in a coma in intensive care units with rhythmic periodic patterns (RPPs) in continuous EEG monitoring that may or may not be ictal, are problematic. In the study, $38 \%$ of the patients had known epilepsy. Second, response to intravenous (i.v.) antiepileptic drugs (AEDs) is good and rapid in the first group, whereas it is hard to evaluate the response to treatment in the second group; no clinical and/or electrophysiologic response to AEDs suggests a non-ictal pattern rather than a drug-resistant NCSE due to these criteria, and on the other hand, some non-ictal

Address for Correspondence/Yazışma Adresi: Ebru Altında $\breve{g}$ MD, Istanbul Bilim University Faculty of Medicine, Department of Neurology, Istanbul, Turkey Phone: +90 5325597119 E-mail: draykutlu@hotmail.com

Received/Geliş Tarihi: 25.12.2016 Accepted/Kabul Tarihi: 25.12.2016

${ }^{\circ}$ Copyright 2017 by Turkish Neurological Society

Turkish Journal of Neurology published by Galenos Publishing House. 
EEG activities responsive to benzodiazepines increase difficulty in diagnosis (4). As a result, they suggested testing the validity of the Salzburg criteria before its use in clinics in a prospective study in patients in an intensive care unit, which would evaluate their outcomes and prognosis.

In a response to the letter, Leitinger et al. (2) stated that the diagnostic accuracy of the Salzburg criteria was high in both groups

Table 1. Salzburg Consensus Criteria for non-convulsive status epilepticus

A. EDs continuously present $\geq 10 \mathrm{~s}$ in patients without known epileptic encephalopathy,

1. EDs $>2.5 \mathrm{~Hz}$,

2. EDs $\leq 2.5 \mathrm{~Hz}$ or rhythmic delta/theta activity $>0.5 \mathrm{~Hz}$, then at least one of the criteria below should be fulfilled to say that these activities are ictal.

Improvement of clinical and EEG features with i.v. AEDs,

a) The insidious presence of accompanying subtle clinical signs,

b) Typical spatiotemporal evolution*

c) In cases of improvement in EEG without clinical improvement or fluctuation** without evolution, this clinical picture is defined as possible NCSE.

B. In addition to the criteria above (A), patients with known epileptic encephalopathy have to fulfill one of the following: 1. Increase in voltage and frequency of EDs in EEG accompanying significant clinical improvement, 2. Improvement of clinical and EEG features with i.v. AEDs.

ED: Epileptic discharges, i.v.: Intravenous, EEG: Electroencephalography, AED: Antiepileptic drugs, NCSE: Non-convulsive status epilepticus.

*Spatiotemporal evolution; at least 2 obvious changes in frequency (by at least $0.5 \mathrm{~Hz}$ ), morphology (at least 2 morphologic changes) and localization (at least 2 electrodes), persisting for at least 3 cycles.

***Fluctuation; $>3$ changes, not more than one minute apart, in frequency (by at least $0.5 \mathrm{~Hz}$ ), morphology (at least 3 changes in at least 2 alternating morphologies) and localization (at least one electrode or others). with different etiologies. As a response to the second criticism, they also specified that the Salzburg criteria could be used without need of secondary criteria and that they were developed to involve various EEG patterns and in diagnostic validation, not for determining prognosis.

As a result, studies are needed on the description, diagnostic criteria, treatment, and prognosis of NCSE. NCSE is a distinct clinic picture although its etiology largely intersects with coma. NCSE should be kept in mind in the differential diagnosis of coma and also while investigating the etiology of coma, and EEG should be performed. However, the ictal-interictal distinction of RPPs in EEG is hard despite the newly defined criteria, which difficulties in clinical use. More intensive training, clinical caution, and prospective studies in large patient groups are needed. Another critical problem is how aggressively NCSE should be treated in coma because the positive or negative impact of treatment of NCSE on prognosis is not known well in this group of patients. The distinction between patients in coma or with severe disease, and those in whom epileptic mechanisms play a role should be made, and treatment should be managed according to this distinction.

\section{References}

1. Altindag E, Okudan ZV, Özkan ST, Krespi Y, Baykan B. Electroencephalographic patterns recorded by continuous EEG monitoring in patients with change of consciousness in the neurological intensive care unit. Archives of Neuropsychiatry 2016.

2. Leitinger M, Beniczky S, Rohracher A, Gardella E, Kalss G, Qerama E, Höfler J, Hess Lindberg-Larsen A, Kuchukhidze G, Dobesberger J, Langthaler PB, Trinka E. Salzburg Consensus Criteria for Non-Convulsive Status Epilepticus: Approach to clinical application. Epilepsy Behav 2015;49:158-163.

3. Leitinger M, Trinka E, Gardella E, Rohracher A, Kalss G, Qerama E, Höfler J, Hess A, Zimmermann G, Kuchukhidze G, Dobesberger J, Langthaler PB, Beniczky S. Diagnostic accuracy of the Salzburg EEG criteria for non-convulsive status epilepticus: a retrospective study. Lancet Neurol 2016;15:1054-1062.

4. Roshdy A, Saleh AS. Salzburg criteria: Can we extend validation to critical care? Lancet Neurol 2017;16:25. 